\title{
Levofloxacin prophylaxis to prevent bacterial infection in chemotherapy- induced neutropenia in acute leukemia
}

\author{
M. Mizanur Rahman and Mohiuddin Ahmed Khan \\ Department of Hematology, Dhaka Medical College, Dhaka 1205, Bangladesh. \\ e-mail: shawon71@yahoo.com
}

\begin{abstract}
Infection in chemotherapy-induced neutropenia (neutrophils $<500 / \mathrm{mm}^{3}$ ) is the main cause of death during the treatment of acute leukemia. Antibiotic prophylaxis is a controversial issue to prevent or delay this infection. This study assessed the efficacy of prophylaxis with oral levofloxacin in chemotherapy-induced febrile neutropenic patients. Eighty patients of acute leukemia was randomly assigned to had levofoxacin (500 mg/daily) or placebo from the starting of chemotherapy. Out of 80 patients 53 developed neutropenia and fever. The number of patients with fever (78\% vs. 68\%), isolation of the pathogenic bacteria $(30.43 \%$ vs. $16 \%)$ was higher and mean starting day of the fever (11.1 vs. 13.2) was shorter in the placebo group than the levofloxacin group. Levofloxacin reduced the bacterial infections and delays the onset of fever in chemotherapy-induced neutropenia especially in short duration $(<7$ days $)$.
\end{abstract}

\section{Introduction}

Infection is the most common and fatal complication associated with neutropenia induced by chemotherapy ${ }^{1}$. During the chemotherapy, the appearance of fever in neutropenia is the first manifestation of a potentially life threatening infection $^{2}$. There is debate on antibiotic prophylaxis during chemotherapy. In one hand, it may reduce the bacterial infection to a neutropenic patient. On the other hand, it may cause the emergence of drug resistant bacteria or fungal infection.

There are many studies on using fluoroquinolone to prevent infection during chemotherapy. Use of oral ciprofloxacin, norfloxacin or enoxacin was showed to reduce gram negative bacterial septicemia ${ }^{3-4}$. Use of fluroquinolone extended spectrum to Gram positive bacteria e.g. levofloxacin or addition of antibiotic effective against Gram positive bacteria reported to reduce the Gram positive septicemia ${ }^{5,6}$. Though there is a concern about the emergence or drug resistant bacteria with the prophylaxis of these antibiotics $^{7,8}$.

In Bangladesh, the prophylaxis is done routinely in the hematology units in fear of infection due to unhygienic conditions in public hospitals. Poverty of patients influences the hematologist to manage the neutropenic fever often without any microbiological culture. The use of antibiotic used in prophylaxis and thereafter is often done without any evidence based guideline. This study tried to evaluate whether prophylaxis with oral levofloxacin can reduce or delay the febrile neutropenic episodes in chemotherapy-induced neutropenia.

\section{Materials and Methods}

The study was a prospective, randomized, placebo controlled, single-blinded study carried out during July 2006 to October 2007. Eighty patients with acute leukemia who were hospitalized and were at risk for chemotherapy-induced neutropenia (absolute neutrophil count $<500 / \mathrm{mm}^{3}$ ) were eligible for the study. All patients entered the study with day 1 of chemotherapy. Patients with a history of hypersensitivity to fluoroquinolones, those treated with antimicrobial therapy in the preceding five days or had fever of infectious origin or a documented infection at the time of enrolment and those presented with neutropenia before chemotherapy were excluded from the study.

At entry, after having provided written informed consent, patients were assigned randomly to receive $500 \mathrm{mg}$ of levofloxacin (Trevox ${ }^{\circledR}$, square pharmaceutical) orally once daily, or an identicalappearing placebo. Prophylaxis was continued in all patients until neutropenia had resolved or 
documentation of fever. Patients were examined daily for clinical signs of infection. In nonneutropenic patients axillary temperature exceeded $101^{\circ} \mathrm{F}$ and in neutropenic patients $\left(\mathrm{ANC}<500 / \mathrm{mm}^{3}\right.$ ) a single oral temperature of $\geq 101^{\circ} \mathrm{F}$ or a temperature of $\geq 100^{\circ} \mathrm{F}$ for $>1$ hour was taken as a sign of infection or septicemia. Appropriate microbiological samples send for the examinations and empirical broad spectrum antibiotics was started. Counting pills monitored compliance.

The primary end point of the study was the occurrence of fever requiring empirical antibacterial therapy during neutropenia. Secondary end points were the type and number of documented infections, the use of parenteral antimicrobial agents during neutropenia, survival at the resolution of neutropenia, compliance, and tolerability.

\section{Enrollment and study design}

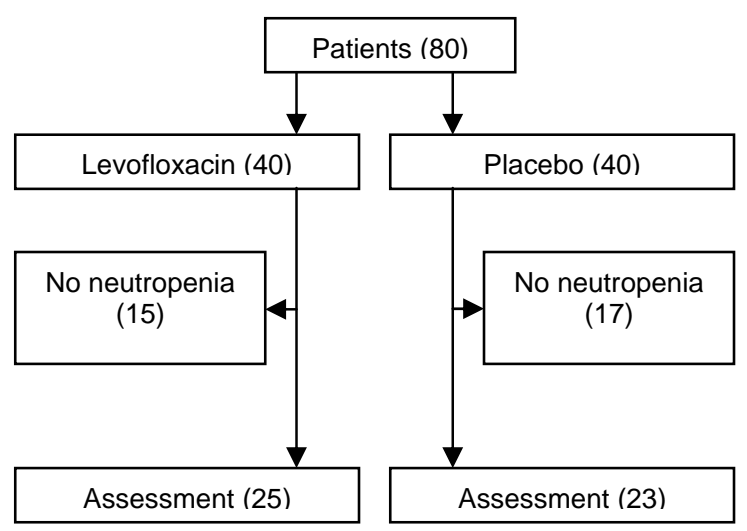

\section{Results}

Eighty adult hospitalized patient with acute leukemia with the risk of chemotherapy induced neutropenia was randomly assigned to had levofloxacin $500 \mathrm{mg}$ or placebo as prophylaxis. Male were more than the female (52 vs 28). ALL was more than the AML (23 vs 45 ). Induction, reinduction and consolidation phase were included in the study. Standard protocol was given to 29 (36.25\%) patient and compromised protocol was given to $51(63.75 \%)$. One patient died during chemotherapy.

The duration and onset of fever in levofloxacin and placebo group was given in Table I. Fever developed 17 patients $(68 \%)$ in levefloxacin group compared to 18 patients $(78 \%)$ in placebo group ( 17 of 25 vs 18 of 23; relative risk 0.87 ; absolute difference in risk- $10 \%, 95 \% \mathrm{CI} ; \mathrm{p}<0.001)$. Microbiological proven infection was 7 (30.43\%) compared to 4 (16\%) placebo group (4 of 25 vs. 7 of 23; relative risk 0.52 ; absolute difference in risk $14.43 \%$; 95\% CI; $p<0.001$; Table II).
The isolation of pathogens $(25.92 \%$ vs. $20 \%)$ was higher in the placebo group than the levofloxacin group (Table III). Most of the pathogenic bacteria are resistant to first line drug that usually prescribed in the hospitals.

Table I. Neutropenia and fever characteristics

\begin{tabular}{lcc}
\hline Characteristic & Levofloxacin & Placebo \\
\hline Duration of fever & & \\
0 days & $15(37.5)$ & $17(42.5)$ \\
1-7 days & $16(40.0)$ & $18(45.0)$ \\
$>7$ days & $9(22.5)$ & $5(12.5)$ \\
Onset of fever & & \\
Present & $17 / 25(68)$ & $18 / 23(78)$ \\
Starting day (mean) & 13.2 & 11.1 \\
Range (day) & $5-20$ & $4-17$ \\
\hline Numbers in parentheses indicate percentage &
\end{tabular}

Numbers in parentheses indicate percentage

Table II. Relative risk of fever and microbiologically proven infection

\begin{tabular}{lccc}
\hline & Levofloxacin & Placebo & $\begin{array}{c}\text { Relative } \\
\text { risk }\end{array}$ \\
\hline Fever & $17 / 25(68)$ & $18 / 23(78)$ & 0.87 \\
$\begin{array}{l}\text { Microbiologically } \\
\text { proven infection }\end{array}$ & $4 / 25(16)$ & $7 / 23(30.43)$ & 0.52 \\
\hline $\begin{array}{l}\text { Numbers in parentheses indicate percentage. 95\% confidence interval; } \\
\mathrm{p}=<0.001\end{array}$
\end{tabular}

Table III. Isolated organisms from samples take from patients

\begin{tabular}{lcc}
\hline & Levofloxacin $(\mathrm{n}=25)$ & Placebo $(\mathrm{n}=23)$ \\
\hline Blood & & 3 \\
E. Coli & 1 & 3 \\
Stphaloccous spp. & 2 & \\
Sputum & & 1 \\
Klebsilla & 0 & \\
Urine & & 0 \\
Candida & 1 & 7 \\
Total & 4 &
\end{tabular}

\section{Discussion}

Prophylaxis with a fluoroquinolone against bacterial infection is quite effective. The number of documented fever and isolation of the pathogenic bacteria were higher in the placebo group than the levofloxacin group. Inversely the mean starting day of the fever was shorter in the placebo group than the levofloxacin group. Several meta-analyses have studied the efficacy of antibiotic prophylaxis compared with control regimen and demonstrated a reduced incidence of various infection-related outcomes and mortality ${ }^{8-10}$. Thirteen patients did not developed fever despite in presence of neutropenia. These patients belong to both levofloxacin and placebo group and so other factors rather than antibiotic prophylaxis was related to this issue.

Out of 80 patients enrolled in this study 53 developed neutropenia and fever. The failure to develop neutropenia is due to some unique feature regarding the characteristics related with the patients, hospital environment and treatment 
protocol in Bangladesh. The ideal isolation for neutropenic patients can not be provided in our hospital. The poor hygiene sense in the community also complicated the situation. Most of the patients cannot afford the full cost of the treatment. This leads compromise in the chemotherapy protocol to avoid or shorten the duration of neutropenia, leading to lessen the complications but in the cost of relapse in long-term.

Fever is directly proportional to the duration of neutropenia. Prolonged neutropenia ( $>7$ days) is a recognized factor for febrile neutropenia ${ }^{6}$. Only 14 patients had prolonged neutropenia. Thirty-four patients enrolled for final assessment had shorter duration of nutropenia (1-7 days) and probably this is the main section where the antibiotic prophylaxis was most beneficial.

Incidence of fever is less in levofloxacin group than the placebo group. Also the mean starting day of the fever is higher in levofloxacin group.

Pathogenic bacteria isolation rate was higher in placebo group. Staphylococcus was almost in equal in number. E. coli was more in placebo group. Gram positive and Gram negative isolates were equal. It may be due to the more coverage to the Gram negative bacteria by levofloxacin. Worldwide there was a predominance of $E$. coli in neutropenic patients, but there was a gradual increase of Gram positive organism. The reason is not still very clear but prophylactic antibiotics against Gram negative bacteria may be a contributing factor ${ }^{9}$. Candida was isolated from urine of one patient. However, the patient was not clinically critically ill. And also it may be related with the levofloxacin prophylaxis. In isolated pathogenic bacteria, most of the pathogens were resistant to first or second line antibiotics. The free antibiotic supplied in hospitals are ampicillin, ciprofloxacin and gentamicin which showed high resistant. Ceftraixone is another drugs which commonly used as first line or second line treatment which also showed a high resistant. So, drugs which are commonly available in our hospital for neutropenic patients are in question. Amikacin, imipenum and meropenum had good sensitivity against most of the pathogens. Fourth generation cephalosporin recommended for monotherapy in febrile neutropenia, was not in the antibiotic sensitivity list and was a drawback of the study. But clinical experience indicates that this may be a suitable alternative.

In conclusion, levofloxacin reduces the bacterial infections and delays the onset of fever in chemotherapy-induced neutropenia especially in short duration of neutropenia ( 7 days) with compromised chemotherapy.

\section{Acknowledgements}

We are acknowledging Bangladesh Medical Research Council for funding the research work and Square Pharmaceutical Ltd. for providing Trevox $500 \mathrm{mg}$ and its identical placebo free of charge.

\section{References}

1. Hughes WT, Armstrong D, Bodey GP, Bow EJ, Brown AE, Calandra T, Feld R, Pizzo PA, Rolston KV, Shenep JL, Young LS. 2002 guidelines for the use of antimicrobial agents in neutropenic patients with cancer. Clin Infect Dis. 2002; 34: 730-51.

2. Bodey GP, Buckley M, Sathe YS, Freireich EJ. Quantitative relationships between circulating leukocytes and infection in patients with acute leukemia. Ann Intern Med. 1966; 64: 328-40.

3. Engels EA, Lau J, Barza M. Efficacy of quinolone prophylaxis in neutropenic cancer patients: A metaanalysis. J Clin Oncol. 1998; 16: 1179-87.

4. Lew MA, Kehoe K, Ritz J, Antman KH, Nadler L, Takvorian T, Mayer R, Kalish L, Finberg R. Prophylaxis of bacterial infections with ciprofloxacin in patients undergoing bone marrow transplantation. Transplantation 1991; 51: 630-36.

5. Karp JE, Merz WG, Hendricksen C, Laughon B, Redden T, Bamberger BJ, Bartlett JG, Saral R, Burke PJ. Oral norfloxacin for prevention of Gram-negative bacterial infections in patients with acute leukemia and granulocytopenia: A randomized, double-blind, placebo-controlled trial. Ann Intern Med. 1987; 106: 17.

6. Talbot GH, Cassileth PA, Paradiso L, Correa-Coronas $\mathrm{R}$, Bond L. Oral enoxacin for infection prevention in adults with acute non-lymphocytic leukemia. Antimicrob Agents Chemother. 1993; 37: 474-82.

7. Bucaneve G, Micozzi A, Menichetti F, Martino P, Dionisi MS, Martinelli G, Allione B, D'Antonio D, Buelli M, Nosari AM, Cilloni D, Zuffa E, Cantaffa R, Specchia G, Amadori S, Fabbiano F, Deliliers GL, Lauria F, Foà R, Del Favero A. Levofloxacin to prevent bacterial infection in patients with cancer and neutropenia. N Engl J Med. 2005; 353: 977-87.

8. Cruciani M, Rampazzo R, Malena M, Lazzarini L, Todeschini G, Messori A, Concia E. Prophylaxis with fluoroquinolones for bacterial infections in neutropenic patients: A meta-analysis. Clin Infect Dis. 1996; 23: 795-805.

9. Kotilainen P, Nikoskelainen J, Huovinen P. Emergence of ciprofloxacin-coagulase-negative staphylococcal skin flora in immunocompromised patients receiving ciprofloxacin. J Infect Dis. 1990; 161: 41-44.

10. Cometta A, Calandra T, Bille J, Glauser MP. Escherichia coli resistant to fluoroquinolones in patients with cancer and neutropenia. N Engl J Med. 1994; 330: 1240-41. 
11. Engels EA, Lau J, Barza M. Efficacy of quinolone prophylaxis in neutropenic cancer patients: A metaanalysis. J Clin Oncol. 1998; 16: 1179-87.

12. Cruciani M, Malena M, Bosco O, Nardi S, Serpelloni G, Mengoli C. Reappraisal with meta-analysis of the addition of Gram-positive prophylaxis to fluoroquinolone in neutropenic patients. J Clin Oncol. 2003; 21: 4127-37.
13. Gafter-Gvili A, Fraser A, Paul M, Leibovici L. Metaanalysis: Antibiotic prophylaxis reduces mortality in neutropenic patients. Ann Intern Med. 2005; 142: 97995.

14. Opepenheim BA. The changing pattern of infection in neutropenic patients. J Antimicrob Chemother. 1998; 41 Suppl D: 7-11. 